\title{
Editorial: Integrative Research on Organic Matter Cycling across Aquatic Gradients
}

\author{
Nicholas D. Ward * \\ Marine Sciences Laboratory, Pacific Northwest National Laboratory, Sequim, WA, USA
}

Keywords: carbon, cycling, aquatic, terrestrial, marine, continuum, gradients, organic

Editorial on the Research Topic

Integrative Research on Organic Matter Cycling across Aquatic Gradients

\section{INTRODUCTION}

The interface between freshwater and marine ecosystems provides a unique setting to examine the evolution of biogeochemical components derived from the landscape, inland waters, estuaries, and the ocean across distinct physiochemical gradients. A diverse body of work exploring this research topic is highlighted here with the goal of integrating our understanding of how organic matter $(\mathrm{OM})$ is transported and transformed along the terrestrial-aquatic continuum and sparking interdisciplinary discussions on future research needs. The movement of water ultimately controls the transport and transformation of geochemical components as they move from land to sea (Ward et al.), and as such, contributions to this research topic will be described within the context of the hydrological cycle, starting with rainfall.

\section{OPEN ACCESS}

Edited and reviewed by:

Eric 'Pieter Achterberg,

GEOMAR Helmholtz Centre for Ocean Research Kiel (HZ), Germany

*Correspondence:

Nicholas D. Ward

nicholas.ward@pnnl.gov

Specialty section:

This article was submitted to

Marine Biogeochemistry,

a section of the journal

Frontiers in Marine Science

Received: 06 April 2017 Accepted: 20 April 2017

Published: 04 May 2017

Citation:

Ward ND (2017) Editorial: Integrative Research on Organic Matter Cycling

across Aquatic Gradients.

Front. Mar. Sci. 4:131.

doi: 10.3389/fmars.2017.00131

\section{TERRESTRIAL FLOW PATHS}

Rainfall passes through terrestrial vegetation and soil layers prior to entering rivers and streams, translocating and transforming carbon in the process. Neu et al. examined the concentration and flux of dissolved organic and inorganic carbon (DOC and DIC, respectively) in each flow path (i.e., rainfall, throughfall, stemflow, soil solution, groundwater, overland flow, and stream flow) in an Amazonian transitional forest. The highest DOC concentrations and fluxes were observed in throughfall and rainfall, particularly during the first storms after the dry season. DOC concentrations were order(s) of magnitude lower in the soils and streams compared to aboveground flowpaths while DIC levels were generally higher, illustrating that rapid transformations begin occurring to DOC before even entering a river network (Neu et al.).

Stubbins et al. evaluated the dissolved organic matter (DOM) composition of throughfall and stemflow in the Southeastern USA based on ultrahigh resolution mass spectrometry and optical properties. DOM composition was primarily related to surface characteristics of the terrestrial vegetation (i.e., tree type and the abundance of epiphytes) and also to the presence of atmospherederived particles, which presumably accumulate during dry periods and are mobilized during the first rainfall events of a water year as observed by Neu et al.

Hernes et al. similarly assessed source inputs of DOM from the landscape to rivers in a temperate watershed in northern California. Leached DOM was extensively transformed as it traveled through the subsurface as indicated by optical analyses and lignin phenol measurements. Hernes et al. further argued that interpretations of lignin biomarkers in water are obscured by complex source signatures and fractionation/transformation of DOM before reaching a main river channel. The take home point from these studies is that a considerable amount of "action" occurs before water and associated OM ever enters a river or stream. 


\section{RIVERS AND STREAMS}

The composition and abundance of $\mathrm{OM}$ in river systems is not only linked to the landscape, as described above, but also to processes occurring in situ. For example, Duan et al. evaluated downstream variability of DOC concentrations in the Mississippi River over a $\sim 20$ year time period. DOC concentrations consistently decreased from the headlands to the river mouth, which was attributed to an imbalance between in situ processing and DOM inputs from floodplains and the landscape. The downstream decrease in DOC concentrations in the Mississippi River is in contrast to the behavior of other large river systems, which was attributed to the historic loss of wetlands in the Mississippi basin (Duan et al.).

The lower reach of the Amazon River is an example of a floodplain-rich system in contrast to the Mississippi River. Sawakuchi et al. assessed $\mathrm{CO}_{2}$ emissions from the lower Amazon River to the atmosphere, which, along with revised estimates for the upper/central Amazon basin, increased the global inland water $\mathrm{CO}_{2}$ emission estimate by $43 \%$. This study highlighted two major gaps in current global $\mathrm{CO}_{2}$ data coverage - tidally-influenced lower rivers and near-shore coastal oceans.

Although the Amazon River is well-known for high rates of $\mathrm{CO}_{2}$ evasion, Gagne-Maynard et al. evaluated the importance of primary production in the Amazon River mainstem, which has typically been assumed to be irrelevant. However, based on an oxygen mass balance, primary production was estimated to occur at roughly $50 \%$ the rate of microbial respiration despite limited light attenuation. Further, constraining this interplay between photosynthesis and respiration is an important step in understanding the underlying mechanisms for both $\mathrm{CO}_{2}$ outgassing and $\mathrm{OM}$ accumulation in large rivers. For example, Bertassoli et al. observed high potential for OM burial since the mid-Holocene in the Amazon's two major lowland clearwater tributaries, the Tapajós and Xingu rivers. Sediment cores showed sharp changes between oxic and anoxic periods attributed to hydrologic patterns, illustrating the potential sensitivity of OM burial to variable conditions caused by factors such as climate change and hydropower operations.

The studies described in Section Terrestrial Flow Paths focused largely on the importance of vegetation on determining the composition and abundance of OM that is ultimately mobilized into river networks. OM derived from biomass burning (i.e., pyrogenic $\mathrm{OM}$ ) is another important source of $\mathrm{OM}$ to the aquatic environment but is less well-studied than vascular plant biomarkers. Myers-Pigg et al. assessed the transport and fate of both dissolved and particulate pyrogenic OM (levoglucosan, specifically) in two Arctic rivers in order to determine the role of sorption and selective partioning on pyrogenic OM decomposition and/or storage. Although certain types of pyrogenic carbon such as levoglucosan have been shown to be bioreactive over short time scales, associations with the particulate phase may result in burial, meaning the signatures of these biomarkers could have potential utility as wildfire indicators in the sediment record (Myers-Pigg et al.). The studies described above collectively illustrate the importance of hydrology on controlling the export, storage, and transformation of $\mathrm{OM}$ in inland waters.

\section{ESTUARIES AND OCEANS}

Various studies examined the transformation of DOM along estuarine and marine gradients. In a southeastern USA marsh-dominated estuary, microbes exhibited a preferential decomposition of marine-derived DOM, resulting in a postincubation predominance of terrestrially-derived DOM, suggesting that this system is effective at exporting terrigenous DOM to the ocean (Medeiros et al.). Terrigenous DOM from sub-Arctic rivers was estimated to have a residence time of 5-7 years in the brackish Baltic Sea, with $50-67 \%$ being exported to the North Sea (Seidel et al.). Similarly, DOM in the temperate Delaware Bay estuary was observed to be relatively unaltered by photo and microbial oxidation on a molecular level along its salinity gradient likely due to high turbidity levels (Osterholz et al.). The relative stability of terrigenous DOM in these estuaries and shelf seas is perhaps indicative of the extensive decomposition that occurs in rivers prior to export or may also illustrate unfavorable environmental conditions for the decomposition of these molecules.

Short-term variability in fluorescent DOM (fDOM) concentrations were evaluated in high resolution throughout a year-long period in the subtropical Shark River estuary, which receives drainage inputs from the Everglades (Regier et al.). fDOM varied from 10 to $50 \%$ during tidal cycles, indicating rapid exchange with mangrove marshes and varied by more than $100 \%$ over multi-day periods due to both precipitation events and water management, illustrating the dynamic behavior of DOM sources, export, and transformation in estuaries. Storm events following long dry periods drastically altered the biogeochemistry of the subtropical Mission-Aransas estuary in Texas. The estuary became significantly less salty and warmer following storm events and large cyanobacteria blooms were observed concurrently with increased nutrient and carbon concentrations, demonstrating the potential role of storms on stimulating estuarine hypoxia (Reyna et al.).

Finally, the behavior of chromophoric DOM (CDOM), DOC, and chlorophyll was evaluated in the Southern Ocean from New Zealand to the western Ross Sea based on satellite remote sensing; all three parameters had the highest concentrations near New Zealand and consistently decreased toward the core of the Antarctic Circumpolar Current (ACC) at higher latitudes (D'Sa and Kim). Temperature and salinity gradients along this transect were primarily controlled by fronts associated with the ACC and the measured parameters were tightly coupled to these physical gradients illustrating the linkage between physical and biogeochemical processes.

The collection of work presented in this Research Topic illustrates the dynamic behavior of OM as it travels with water through the terrestrial biosphere, river networks, estuaries, and oceans. The fate of OM in the aquatic environment is closely tied to both its previous history and its present physical and biological surroundings. As such, it is essential to consider how OM has 
already evolved prior to and after being exported from any given location along the continuum.

\section{AUTHOR CONTRIBUTIONS}

The author confirms being the sole contributor of this work and approved it for publication.

\section{FUNDING}

This work was supported by NSF DEB Grant \#1256724, FAPESP Grant \#08/58089-9, the Gordon and Betty Moore Foundation Marine Microbial Initiative, and the University of Florida Jon L. and Beverly A. Thompson Endowment.

\section{ACKNOWLEDGMENTS}

I would like to thank all of the authors who contributed to the Frontiers in Marine Science Research Topic: Integrative
Research on Organic Matter Cycling Across Aquatic Gradients, the reviewers who kindly dedicated their time to the peerreview process, the Frontiers editorial team, and the editors of the Research Topic: Thomas Bianchi, Richard Keil, Patricia Medeiros, Michael Seidel, and Carol Robinson. I would also like to thank the Gordon and Betty Moore Foundation Marine Microbial Initiative for their generous donation to support open access publication fees for the Research Topic.

Conflict of Interest Statement: The author declares that the research was conducted in the absence of any commercial or financial relationships that could be construed as a potential conflict of interest.

Copyright (c) 2017 Ward. This is an open-access article distributed under the terms of the Creative Commons Attribution License (CC BY). The use, distribution or reproduction in other forums is permitted, provided the original author(s) or licensor are credited and that the original publication in this journal is cited, in accordance with accepted academic practice. No use, distribution or reproduction is permitted which does not comply with these terms. 